\title{
Faktor-Faktor Yang Mempengaruhi Organizational Citizenship Behavior Pada Karyawan Swasta di Provinsi Yogyakarta
}

\author{
Nala Tri Kusuma ${ }^{1}$, Gendro Wiyono ${ }^{2}$, Ambar Lukitaningsih ${ }^{3}$ \\ Program Studi Magister Manajemen, Universitas Sarjanawiyata Tamansiswa, \\ Yogyakarta, Indonesia
}

\section{Info Artikel}

Sejarah Artikel:

Diterima : 19 November 2019

Disetujui : 21 November 2019

Dipublikasikan : 3 Februari 2020

\section{Keywords:}

perceived co-worker, perceived supervisior support, perceived organizational support, employee participation in decision making, career development, safety and health compliance pada job satisfaction and organizational citizenship behavior.

\begin{abstract}
Abstrak
Tujuan dari penelitian ini adalah untuk menguji perceived co-worker, perceived supervisior support, perceived organizational support, employee participation in decision making, career development, safety and health compliance pada job satisfaction dan organizational citizenship behavior. Metode yang digunakan dalam penelitian ini adalah metode kuantitatif dengan teknik accidental sampling. Hasil penelitian menunjukkan bahwa dukungan atasan yang dirasakan dan pengembangan karir memiliki pengaruh yang signifikan terhadap kepuasan kerja. Studi ini menemukan bahwa perceived co worker, perceived organizational support, employee participation in decision making, dan safety and helath compliance tidak berpengaruh pada job satisfaction. Hasil penelitian menunjukkan bahwa persepsi dukungan atasan, pengembangan karir, keselamatan dan kepatuhan kesehatan memiliki pengaruh yang signifikan terhadap organizational citizenship behavior. Penelitian ini menemukan bahwa dukungan rekan kerja, dukungan organisasi yang dirasakan, partisipasi karyawan dalam pengambilan keputusan, tidak mempengaruhi organizational citizenship behavior, dan hasilnya menunjukkan bahwa kepuasan kerja dimediasi antara pengembangan karir menuju perilaku kewarganegaraan organisasi.

The purpose of the research is to test the effect of perceptions of coworkers, perceptions of supervisior support, perceptions of organizational support, employee participation in decision making, career development, and safety and health compliance on job satisfaction and organizational citizenship behavior. The method used in this study is a quantitative method with accidental sampling technique. The results showed that perceived supervisior support and career development had a significant effect on job satisfaction. This study found that perceived co worker, perceived organizational support, employee participation in decision making, and safet and helath compliance had not affect job satisfaction. The results showed that perceived supervisior support, career development, safety and health compliance had a significant effect on organizational citizenship behavior. This study found that perceived co worker, perceived organizational support, employee participation in decision making, had not affect organizational citizenship behavior and the result showed that job satisfaction mediated between career development toward organizational citizenship behavior.
\end{abstract}

Alamat Korespondensi:

Jalan Kusumanegara 121

email: nalatri9kusuma@gmail.com
ISSN

2502-1818 (cetak)

2615-7918 (online) 


\section{PENDAHULUAN}

\section{Latar Belakang}

Manusia secara individu maupun kelompok mempunyai peran mendasar dalam pencapaian visi perusahaan. Perusahaan barangkali telah memiliki sumber daya manusia terampil, namun tidak berdampak besar dalam kontribusinya mencapai visi (Akram et al., 2018). Perusahaan dihadapkan pada permasalahan pekerja terampil memiliki kinerja biasa-biasa saja dan hanya memenuhi kewajiban saja, atau menjadi lebih tinggi kinerjanya ketika ada stimulan. Karyawan yang hanya memenuhi tugas pokoknya saja, seringkali nampak sebagai karyawan baik, namun sebenarnya karyawan tersebut menyimpan potensi menganggur Rich, Jeffrey, dan Eean (2010)

Menggunakan populasi pegawai swasta di Provinsi Yogyakarta, penelitian ini ingin menganalisis kontribusi pekerja terhadap perusahaannya. Fenomena karyawan yang berkontribusi pada organisasi sehingga dapat bekerja dan memenuhi ekspetasi dari organisasi, menjadi satu alasan untuk dilakukan penelitian, dengan menggunakan mediasi kepuasan kerja yang selanjutnya akan berdampak pada organizational citizenship behavior (OCB) yang menekankan pentingnya mengusahakan pekerja handal berkontribusi bagi organisasi (Prakoso \& Anita Listiara, 2017) menarik untuk diteliti dengan melihat faktor apa saja yang mempengaruhi.

Penelitian ini juga menarik untuk dilakukan karena karyawan yang bekerja di Provinsi Yogyakarta sebagian dari mereka ternyata adalah bekerja pada perusahaan swasta. Berbeda dengan karyawan yang bekerja sebagai Pegawai Negeri Sipil (PNS), ketika mereka malas untuk bekerja mereka tetap mendapatkan gaji atas kinerja yang dilakukan, sedangkan karyawan diperusahaan swasta ditutut untuk dapat bersaing dan memiliki skill yang menguntungkan bagi perusahaannya sehingga dapat bersaing dengan perusahaan lain.

\section{Landasan Teori}

Penelitian menggunakan pendekataan teori RBV. Pada strategi RBV ini menyatakan bahwa perusahaan bersaing dengan sumber daya dan kemampuannya (Wernerfelt, 1984). Perusahaan yang memiliki sumber daya yang besar memiliki keunggulan kompetitif dalam bentuk kemampuan untuk menciptakan nilai yang lebih dibandingkan para pesaingnya. Para manajer perusahaan perlu memahami area persaingan dan kemampuan pesaingnya, sehingga sumber daya yang dimiliki mampu bersaing dengan perusahaan yang lain dan memenuhi tujuan perusahaan (Kozlenkova, Samaha, \& Palmatier, 2014)

Bentuk startegi yang diperlukan oleh perusahaan dalam memenuhi sumber daya yang dimiliki agar dapat bersaing dengan perusahaan lain adalah dengan melihat faktor apa saja yang mempengaruhi karyawan agar dapat memiliki organizational citizenship behavior dengan melihat dari perceived co-worker, perceived supervisior support, perceived organizational support, employee participation in decision making, career development, safety and health compliance, dan job satisfaction.

\section{Pengembangan Hipotesis}

Dukungan rekan kerja berbeda dengan dukungan atasan maupun dukungan organisasi, dukungan rekan kerja lebih pada rasa sosial-emosional antar rekan kerja Penelitian terdahulu mendefinisikan bahwa dukungan rekan kerja sebagai sejauh mana karyawan percaya rekan kerja mereka bersedia memberi bantuan yang terkait dengan pekerjaan untuk membantu dalam pelaksanaan tugas, dengan adanya 
dukungan rekan kerja karyawan akan mempengaruhi kepuasan kerja karyawan. Dukungan rekan kerja berhubungan positif dengan kepuasan kerja karyawan, keterlibatan kerja, dan komitmen organisasi Karena rekan kerja tetap pada hierarki yang sama dengan karyawan utama di dalamnya organisasi, kita dapat mengharapkan bahwa sifat dukungan yang didapat dari rekan kerja mungkin tidak sama dengan dukungan yang diperoleh dari organisasi (Matijaš \& Brdovčak, 2018). Dengan demikian, karyawan hubungan pertukaran sosial dengan rekan kerja mungkin memiliki pengaruh tambahan pada sikap dan kinerja pekerjaan mereka yang menghasilkan kepuasan kerja bagi karyawan.

H1: Perceived Co-Worker berpengaruh positif dan signifikan terhadap job satisfaction.

Teori COR menunjukkan bahwa kelelahan emosional muncul ketika pekerja melihat kurangnya sumberdaya untuk melakukan pekerjaan mereka dan ketika pekerja tahu kalau sumberdaya tidak cukup untuk memenuhi permintaan pekerjaan atau ketika tambahan dukungan personil tidak menyediakan hasil yang diinginkan (Yang et al., 2018). Oleh karena itu, individu dengan sumber daya kerja berlebih cenderung diinvestasikan kembali di organisasi. Pengawas yang mendukung bertindak sebagai sumber daya organisasi yang memberikan panduan, bantuan, dan umpan balik kepada bawahan. Akibatnya, individu dengan sumber daya berlebih dan menerima dukungan dari atasan dengan baik cenderung menginvestasikan kembali sumber daya ini ke dalam pekerjaan mereka untuk mencapai hasil karir yang lebih baik dalam hal tingkat kepuasan karir dan kemampuan promosi yang tinggi. Penelitian terdahulu mendukung bahwa Perceived Supervisior Support berpengaruh terhadap Job
Satisfaction (Maden \& Kabasakal, 2014; Yang et al., 2018).

\section{H2: Perceived Supervisior Support berpengaruh terhadap Job Satisfaction}

Seorang karyawan dalam organisasi tidak hanya menilai kepuasan dan loyalitas mereka hanya melalui dukungan organisasi saja, untuk menilai persepsi karyawan bahwa organisasi mereka menghargai kontribusi dan kepedulian mereka tentang kesejahteraan mereka (Mayes et al., 2017), dukungan organisasi berperan penting dalam meningkatkan kinerja pegawai yang akan mempengaruhi kepuasan kerja karyawan terhadap organisasi ditempat bekerja (Maden \& Kabasakal, 2014). Seorang karyawan dalam organisasi tidak hanya menilai kepuasan dan loyalitas mereka hanya melalui dukungan organisasi saja, untuk menilai persepsi karyawan bahwa organisasi mereka menghargai kontribusi dan kepedulian mereka tentang kesejahteraan mereka (Mayes et al., 2017), dukungan organisasi berperan penting dalam meningkatkan kinerja pegawai yang akan mempengaruhi kepuasan kerja karyawan terhadap organisasi ditempat bekerja (Maden \& Kabasakal, 2014).

H3: Perceived Organizational Support berpengaruh positif dan signifikan terhadap job satisfaction.

Partisipasi dalam pengambilan keputusan meningkatkan kualifikasi dan keterampilan karyawan dan akibatnya memungkinkan mereka untuk mendapatkan pekerjaan yang lebih baik. Menurut prinsip timbal balik, karyawan akan menanggapi peningkatan daya tarik dan kondisi ini dengan sikap yang lebih positif dan perilaku terhadap perusahaan. Penelitian sebelumnya menunjukkan bahwa partisipasi dalam pengambilan keputusan membuat perubahan dalam praktik kerja, kondisi, dan penghargaan, dan berkorelasi dengan kepuasan kerja 
(Scott-Ladd, Travaglione, \& Marshall, 2006; Muindi, 2014).

H4: Employee Participation in Decision Making berpengaruh positif dan signifikan terhadap job satisfaction.

Kepuasan kerja menunjukkan kesenangan perasaan karyawan yang timbul sebagai akibat dari penilaian aspek pekerjaan atau pengalaman kerja. Aspek kerja karena pekerjaan itu sendiri meliputi promosi, pengawasan, bisnis mitra, kondisi kerja, tantangan, dan komunikasi. Jika kondisi aspek kerja karyawan adalah memuaskan, itu akan memberikan semangat yang kuat bagi karyawan untuk berkinerja lebih baik (Saleem, Kamran, Sabir, \& Iqbal, 2013)

Munculnya kepuasan kerja antara lain didorong oleh faktor pengembangan karier yang mengalami kemajuan dengan baik. Pengembangan karier dalam suatu organisasi adalah salah satu objek penting, sehingga dapat memberi pengaruh pada sikap dan perilaku karyawan serta kondisi emosional mereka. Seperti yang dibahas sebelumnya, kepuasan kerja itu menunjukkan perasaan yang menyenangkan atau emosional kondisi. Karena itu, jika seorang karyawan memiliki persepsi yang baik tentang implementasi pengembangan karir, dapat memberikan yang positif berdampak pada munculnya kepuasan kerja. Dengan perkembangan dari karir yang baik, itu akan memungkinkan karyawan mendapatkan promosi dengan cepat, menikmati pekerjaan mereka dengan senang hati, dan merasa tertantang, sehingga karyawan puas dengan kondisi tersebut (Naway \& Haris, 2017).

H5: Career Development berpengaruh terhadap Job Satisfaction

Keselamatan dan kesehatan selalu menjadi daftar teratas dalam organisasi karena dampaknya yang usia, aset dan reputasi perusahaan. Karena keselamatan dan kesehatan merupakan faktor penting untuk menurunkan kecelakaan dan cedera di tempat kerja. Kepatuhan keselamatan dan kesehatan mengacu pada kegiatan inti yang perlu dilakukan individu agar dapat dipertahankan di tempat kerja. Hal yang perlu diperhatikan dalam menunjang keselamatan ditempat kerja seperti menggunakan alat pelindung diri dengan benar, penanganan bahan kimia berbahaya dengan aman dan mematuhi standar prosedur dan peraturan (Puah, Ong, \& Chong, 2016). Keselamatan dan kesehatan kerja dapat mempengaruhi kepuasan karyawan pada organisasi, dengan adanya keselamatan dan kesehatan di tempat kerja dapat menggambarkan bahwa organisasi peduli dengan keselamatan dan kesehatan karyawan di tempat bekerja. Dengan demikian, kepatuhan keselamatan dan kesehatan merupakan aspek penting kontrol bagi organisasi untuk meningkatkan tingkat keselamatan dan hasil kesehatan (Game, 2007).

H6: Safety and Health Compliance berpengaruh positif dan signifikan terhadap job satisfaction

Kepuasan karyawan juga tergantung pada hubungan di antara rekan kerja para karyawan. Rekan kerja adalah pengaruh sosial yang penting khususnya dalam bidang komunikasi. Dengan adanya dukungan dari rekan kerja akan cenderung merasa bahwa dengan tugas yang banyak dari dukungan sosial seseorang akan memperbaiki fisik yang lebih baik dan stres yang yang dialaminya akan berkurang, sehingga mereka tidak merasa terbebani dengan tugas yang diberikan sehingga akan meningkatkan kinerja dari karyawan yang akan mengarah pada adanya sikap OCB (Farrell \& Finkelstein, 2011).

H7: Perceived co-worker berpengaruh positif dan signifikan terhadap organizational citizenship behavior 
Menurut teori pertukaran sosial dan norma timbal balik dapat dirasakan ketika seorang atasan mendukung bawahan kemudian bawahan merasa berkewajiban untuk menanggapi dan mendukung atasan mereka (Khan, Mahmood, Kanwal, \& Latif, 2015). Respon karyawan terhadap perilaku atasan adalah dengan berperilaku dengan cara yang menguntungkan dan mendukung yang sering disebut sebagai OCB (Kartika, Kaihatu, Adiwijaya, \& Nugroho, 2017). Sebaliknya, karyawan, yang menganggap bahwa atasan mereka kurang mendukung, karyawan akan menunjukkan perilaku yang rendah terhadap organisasi seperti malas dalam melaksanakan tugas kantor. Jadi, pengawas memainkan peran penting dalam memotivasi. Dukungan atasan dan kepercayaan pada supervisor adalah konstruksi yang berbeda tetapi sangat berkorelasi dan sosial. Teori pertukaran menyatakan bahwa kepercayaan adalah unsur wajib untuk hubungan timbal balik antara atasan dan bawahan (Akram, Kamran, Iqbal, Habibah, \& Atif Ishaq, 2018; Kartika et al., 2017; Yui-Tim Wonga, 2012).

H8: Perceived Supervisior Support berpengaruh terhadap Organizational Citizenship Behavior

Seorang karyawan tidak hanya menilai kepuasan dan komitmen mereka hanya melalui dukungan atasan ditempat mereka bekerja, dukungan organisasi juga menjadi faktor penting karyawan ingin terlibat dalam pekerjaan didalam organisasi (Xiao, Wang, Li, \& Ma, 2017). OCB mengacu pada perilaku terkait pekerjaan yang melampaui tugas utama karyawan yang sudah ditentukan oleh organisasi. Beberapa contoh OCB termasuk memberikan bantuan ekstra kepada rekan kerja, menjadi relawan untuk kegiatan kerja khusus, tepat waktu, dan membuat saran ketika masalah muncul. Penelitian terdahulu menunjukkan bahwa karyawan yang melaporkan POS lebih tinggi memiliki ikatan sosial yang lebih kuat dengan organisasi, yang pada gilirannya mengarah ke lebih banyak OCB (Wong \& Ngo, 2012; Newman, Nielsen and Miao, 2015).

H9: Perceived Organizational Support berpengaruh terhadap Organizational Citizenship Behavior

Dalam organisasi, proses pengambilan keputusan akan dipengaruhi oleh banyak faktor, terutama struktur organisasi dan stabilitas atau ketidakstabilan faktor lingkungan yang berpengaruh. Pengambilan keputusan organisasi adalah proses mengidentifikasi dan menyelesaikan masalah. Proses ini melibatkan dua langkah utama. Tahap identifikasi masalah, kapan informasi tentang kondisi organisasi dan lingkungan dipantau tentukan apakah kinerja memuaskan atau tidak. Keputusan organisasi, dalam hal kompleksitasnya berbeda dan mereka dapat dibagi sebagai keputusan yang terencana dan tidak terencana (Scott-Ladd, Travaglione \& Marshall, 2006). Keputusan yang direncanakan berulang dan jelas, dan untuk menyelesaikan masalah ada beberapa yang pasti metode dan prosedur. Organisasi yang baik tidak hanya mendengarkan pendapat dari satu pihak harus ada timbal balik antara atasan dengan karyawannya, akibatnya, perlu diketahui bahwa mereka yang terlibat dalam keputusan organisasi, umumnya lebih optimis tentang pekerjaan mereka dan berpartisipasi dalam pengambilan keputusan organisasi, karyawan juga akan meningkatkan sikap perhatian terhadap organisasi dan akan meningkatkan keterlibatan dengan karyawan dalam organisasi (Veshaghi, 2016).

H10: Perceived Organizational Support berpengaruh terhadap Organizational Citizenship Behavior

Dalam organisasi, proses pengambilan keputusan akan dipengaruhi oleh banyak faktor, terutama struktur organisasi dan 
stabilitas atau ketidakstabilan faktor lingkungan yang berpengaruh. Pengambilan keputusan organisasi adalah proses mengidentifikasi dan menyelesaikan masalah. Proses ini melibatkan dua langkah utama. Tahap identifikasi masalah, kapan informasi tentang kondisi organisasi dan lingkungan dipantau tentukan apakah kinerja memuaskan atau tidak. Keputusan organisasi, dalam hal kompleksitasnya berbeda dan mereka dapat dibagi sebagai keputusan yang terencana dan tidak terencana (Scott-Ladd, Travaglione \& Marshall, 2006). Keputusan yang direncanakan berulang dan jelas, dan untuk menyelesaikan masalah ada beberapa yang pasti metode dan prosedur. Organisasi yang baik tidak hanya mendengarkan pendapat dari satu pihak harus ada timbal balik antara atasan dengan karyawannya, akibatnya, perlu diketahui bahwa mereka yang terlibat dalam keputusan organisasi, umumnya lebih optimis tentang pekerjaan mereka dan berpartisipasi dalam pengambilan keputusan organisasi, karyawan juga akan meningkatkan sikap perhatian terhadap organisasi dan akan meningkatkan keterlibatan dengan karyawan dalam organisasi (Veshaghi, 2016).

\section{H11: Employee Particaption in Decision Making berpengaruh terhadap Organizational Citizenship Behavior}

$\begin{array}{ccr}\text { Organisasi } & \text { yang } & \text { memberdayakan } \\ \text { manajemen } & \text { lebih } & \text { cenderung }\end{array}$ memperhatikan tentang kinerja karyawan. Peneliti terdahulu memberikan pemahaman pekerjaan sebagai pola pikir dan memberikan pemahaman yang berbeda. Penyediaan program pengembangan karir yang tepat yang mampu meningkatkan sikap OCB pada karyawan (Carmeli, Shalom, \& Weisberg, 2007). Sikap OCB pada karyawan dapat meningkatkan komitmen organisasi dan mengurangi niat karyawan untuk meninggalkan perusahaan. Bisnis-yang tidak menawarkan program pengembangan karir yang menarik yang dapat kehilangan karyawan yang baik karena pesaing menawarkan peluang kerja (Al-Shawabkeh, 2017)

H12: Career Development berpengaruh terhadap Organizational Citizenship

Hubungan antara kepuasan kerja dan perilaku karyawan (OCB) telah dilakukan oleh banyak peneliti, karena hubungan timbal balik antara kepuasan kerja dan OCB dapat mempertahankan karyawan di dalam organisasi dan meningkatkan kepuasan kerja karyawan didalam organisasi. Hubungan karyawan yang cenderung memenuhi kebutuhan organisasi akan melampaui panggilan tugas untuk membantu rekan kerja. Akibatnya, tingkat kepuasan kerja yang lebih tinggi akan menyebabkan tingkat altruisme OCB yang lebih tinggi (Ladebo, 2008; Tang, 2008).

\section{H13: Job Satisfaction berpengaruh terhadap Organizational Citizenship Behavior}

\section{METODE}

Penelitian ini menggunakan metode penlitian kuantitatif dengan teknik pengambilan sampel accidental sampling. Jumlah sampel yang digunakan dalam penelitian ini berjumlah 238 karyawan yang bekerja di perusahaan swasta di Yogyakarta. Data penelitian ini diuji menggunakan SmartPLS 3.0. Indikator kuesioner yang digunakan dalam penelitian mengadaptasi dari penelitian Perceived CoWorkers (Puah, Ong, \& Chong, 2016), Perceived Supervisor Support ( (Puah, Ong, \& Chong, 2016), Perceived Organizational Support (Puah, Ong, \& Chong, 2016), Employee Participation In Decision Making (Huo \& Boxall, 2018), Career Development (Zhang, Farh \& Wang, 2011), Safety and Health Compliance (Puah, Ong, \&Chong, 2016), Job Satisfaction (Crow, Lee \& Joo, 2012), dan Organizational Citizenship Behavior (Shim \& Rohrbaugh, 2014) 


\section{HASIL DAN PEMBAHASAN}

\section{Validitas dan Reliabilitas}

Item uji validitas dikatakan valid jika nilai $\mathrm{r}$ hitung $\geq \mathrm{r}$ tabel (0.1161). Pengujian pearson correlation menghasilkan $\mathrm{r}$ hitung perceived coworker $(0,535$ s.d. 0,758$)$, perceived supervisior support $(0,728$ s.d. 0,803), perceived organizational support $(0,676$ s.d. 0,853), employee participation in decision making $(0,446$ s.d. 0,681), career development $(0,617)$, safety and health compliance $(0,349$ s.d. 0,503$)$, job satisfaction $(0,565$ s.d. 0,712$)$, dan organizational citizenship behavior

(0,668 s.d. 0,747) > 0.1161. Cronbach's Alpha Based on Standardized Items perceived co-worker $(0,861)$, perceived supervisior support $(0,926)$, perceived organizational support $(0,908)$, employee participation in decision making $(0,840)$, career development $(0,763)$, safety and health compliance (0,628), job satisfaction $(0,784)$, dan organizational citizenship behavior $(0,877)>0,7$ atau instrumen reliabel. Hasil menunjukkan data adalah valid dan reliabel untuk digunakan dalam pengujian lebih lanjut

\section{HASIL DAN PEMBAHASAN}

Karakteristik responden pada Tabel 1 menunjukkan lebih banyak karyawan wanita (40,3\%), pendidikan terakhir SLTA $(50,4 \%)$, berdasar usia didominasi 20-30 tahun $(71,8 \%)$, dan kebanyakan baru bekerja $1-5$ tahun $(79 \%)$.

Tabel 1 Karateristik Responden

\begin{tabular}{lll}
\hline Karakteristik & \multicolumn{1}{c}{ Keterangan } & $\%$ \\
\hline \multirow{2}{*}{ Jender } & Pria & 40,3 \\
& Wanita & 59,7 \\
\hline \multirow{3}{*}{ Pendidikan } & SLTP & 2,9 \\
& SLTA & 50,4 \\
& Diploma & 12,2 \\
& S1/S2/S3 & 34,5 \\
\hline \multirow{4}{*}{ Usia } & Kurang dari 20 & 14,3 \\
& tahun & \\
& 20-30 tahun & 71,8 \\
& 31-40 tahun & 9,2 \\
& 41-50 tahun & 3,8 \\
& Diatas 50 & 0,8 \\
& tahun & \\
\hline \multirow{4}{*}{ Masa Kerja } & $1-5$ tahun & 79,0 \\
& 6-10 tahun & 17,6 \\
& 11-15 tahun & 0,8 \\
& $>15$ tahun & 2,5 \\
\hline Sumber $:$ Data Primer diolah, 2019
\end{tabular}

Sumber : Data Primer, diolah, 2019

\section{Uji Indikator}

Validitas konvergen diuji tabel, itu menunjukkan semua indikator menggunakan outer loading dari hasil memiliki validitas lebih besar dari 0,7. 
Oleh karena itu, indikator yang digunakan menggambarkan setiap konstruk yang dalam penelitian ini telah cukup akan diukur.

Tabel 2 Karateristik Responden

\begin{tabular}{l|l|l|l|l|l|l|l|l|l}
\hline ITEM & $\begin{array}{l}\text { X1 } \\
\text { CO- } \\
\text { WORKER }\end{array}$ & $\begin{array}{l}\text { X2 } \\
\text { PSS }\end{array}$ & $\begin{array}{l}\text { X3 } \\
\text { POS }\end{array}$ & $\begin{array}{l}\text { X4 } \\
\text { EPD }\end{array}$ & $\begin{array}{l}\text { X5 } \\
\text { CD }\end{array}$ & $\begin{array}{l}\text { X6 } \\
\text { SHC }\end{array}$ & $\begin{array}{l}\text { Y1 } \\
\text { JS }\end{array}$ & $\begin{array}{l}\text { Y2 } \\
\text { OCB }\end{array}$ & KETERANGAN \\
\hline PCW1 & 0,921 & & & & & & & & valid \\
\hline PCW2 & 0,939 & & & & & & & & valid \\
\hline PSS1 & & 0,908 & & & & & & & valid \\
\hline PSS2 & & 0,896 & & & & & & & valid \\
\hline PSS3 & & 0,910 & & & & & & & valid \\
\hline POS1 & & & 0,854 & & & & & & valid \\
\hline POS2 & & & 0,961 & & & & & & valid \\
\hline EPD1 & & & & 0,895 & & & & & valid \\
\hline EPD2 & & & & 0,901 & & & & & valid \\
\hline CD1 & & & & & 0,906 & & & & valid \\
\hline CD2 & & & & & 0,892 & & & & valid \\
\hline SHC1 & & & & & & 0,917 & & & valid \\
\hline SHC2 & & & & & & 0,794 & & & valid \\
\hline JS1 & & & & & & & 0,881 & & valid \\
\hline JS3 & & & & & & & 0,888 & & valid \\
\hline OCB1 & & & & & & & & 0,871 & valid \\
\hline OCB2 & & & & & & & & 0,906 & valid \\
\hline OCB3 & & & & & & & & 0,845 & valid \\
\hline Subr: Data Princr
\end{tabular}

Sumber : Data Primer, Diolah, 2019

Standardized Root Mean Square Residual (SRMR) menilai rata-rata perbedaan antara korelasi yang diamati dan diharapkan. Nilai SRMR 0,058<0,10 yang merupakan goodness of fit measure untuk PLS-SEM yang dapat digunakan untuk menghindari misspecification model (Henseler et al., 2014). Nilai Chi-Square $0,660<1.652$ artinya jumlah variabel manifes dalam model jalur PLS dan jumlah variabel independen dalam model matriks kovarian tercukupi. Nilai NFI 0,676, jika nilai NFI mendekati nilai 1 semakin baik kecocokannya. Nilai RMS_theta 0,231 jika nilai rms_theta dibawah 0,12 mengindikasikan model yang pas

\section{Tabel 3 Hasil Uji Fit Summary}

\begin{tabular}{lr}
\hline & $\begin{array}{c}\text { Estimated } \\
\text { Model }\end{array}$ \\
\hline SRMR & 0,058 \\
Chi-Square & 660,241 \\
NFI & 0,676 \\
rms Theta & 0,231 \\
\hline Sumber : Data Primer, Diolah, 2019
\end{tabular}

\section{Uji Hipotesis}

Berdasarkan hasil hipotesis yang dibuat dapat dilihat bahwa hipotesis yang

diterima terdapat pada variabel perceived supervisior support terhadap job 
satisfaction dengan nilai signifikansi 0,014, career development terhadap job satisfaction dengan nilai signifikansi 0,000 , perceived supervisior support terhadap organizational citizenship behavior dengan nilai signifikansi 0,000, career development terhadap organizational citizenship behavior dengan nilai signifikansi 0,039 , dan safety and health compliance terhadap organizational citizenship behavior dengan nilai signifikansi 0,000 .

Tabel 4 Path Coefficients

\begin{tabular}{|c|c|c|c|c|}
\hline & $\begin{array}{l}\text { Original } \\
\text { Sample } \\
(\mathrm{O})\end{array}$ & $\begin{array}{l}\text { T Statistics } \\
(|\mathrm{O} / \mathrm{STDEV}|)\end{array}$ & P Values & Keterangan \\
\hline $\begin{array}{lllll}\begin{array}{l}\text { Perceived } \\
\text { Satisfaction }\end{array} & \text { Worker } & \rightarrow & \text { Job } \\
\end{array}$ & 0,129 & 1,514 & 0,131 & Tidak Terbukti \\
\hline $\begin{array}{l}\text { Perceived Supervisior Support }->\text { Job } \\
\text { Satisfaction }\end{array}$ & 0,0262 & 2,465 & 0,014 & Terbukti \\
\hline $\begin{array}{l}\text { Perceived Organizational Support }-> \\
\text { Job Satisfaction }\end{array}$ & $-0,120$ & 1,529 & 0,127 & Tidak Terbukti \\
\hline $\begin{array}{l}\text { Employee Participation in Decision } \\
\text { Making -> Job Satisfaction }\end{array}$ & 0,058 & 0,903 & 0,367 & Tidak Terbukti \\
\hline $\begin{array}{llll}\text { Career Development } & \rightarrow & \text { Job } \\
\text { Satisfaction } & & & \end{array}$ & 0,258 & 3,819 & 0,000 & Terbukti \\
\hline $\begin{array}{l}\text { Safety and Health Compliance -> Job } \\
\text { Satisfaction }\end{array}$ & 0,062 & 1,076 & 0,283 & Tidak Terbukti \\
\hline $\begin{array}{l}\text { Perceived Co } \quad \text { Worker } \\
\text { Organizational Citizenship Behavior }\end{array}$ & $-0,041$ & 0,609 & 0,543 & Tidak Terbukti \\
\hline $\begin{array}{l}\text { Perceived Supervisior Support } \quad \rightarrow \\
\text { Organizational Citizenship Behavior }\end{array}$ & 0,335 & 4,367 & 0,000 & Terbukti \\
\hline $\begin{array}{l}\text { Perceived Organizational Support -> } \\
\text { Organizational Citizenship Behavior }\end{array}$ & $-0,034$ & 0,553 & 0,580 & Tidak Terbukti \\
\hline $\begin{array}{l}\text { Employee Participation in Decision } \\
\text { Making -> Organizational Citizenship } \\
\text { Behavior }\end{array}$ & 0,029 & 0,508 & 0,611 & Tidak Terbukti \\
\hline $\begin{array}{l}\text { Career Development -> Organizational } \\
\text { Citizenship Behavior }\end{array}$ & 0,146 & 2,073 & 0,039 & Terbukti \\
\hline $\begin{array}{l}\text { Safety and Health Compliance }-> \\
\text { Organizational Citizenship Behavior }\end{array}$ & 0,252 & 4,709 & 0,000 & Terbukti \\
\hline $\begin{array}{l}\text { Job Satisfaction -> } \text { Organizational } \\
\text { Citizenship Behavior }\end{array}$ & 0,168 & 2,890 & 0,004 & Terbukti \\
\hline
\end{tabular}

Sumber : Data Primer, diolah, 2019

\section{Uji Sobel test}

Berdasarkan hasil uji sobel yang dilakukan dapat dlihat bahwa variabel yang dapat memediasi dengan membandingkan $\mathrm{T}$ hitung dan $\mathrm{T}$ tabel development terhadap organizational citizenship behavior dengan nilai signifikansi 2,3022,302>1,98 dengan adalah pada variabel career development. tingkat signifikansi 5\% Job satisfaction mampu memediasi career 


\begin{tabular}{llll}
\hline \multicolumn{1}{c}{ Variabel } & T Hitung & T Tabel & Keterangan \\
\hline $\begin{array}{l}\text { Perceived Co Worker-Job Satisfaction-Organizational } \\
\text { Citizenship Behavior }\end{array}$ & 1,344 & 1,98 & Tidak Terbukti \\
\hline $\begin{array}{l}\text { Perceived Supervisior Support-Job Satisfaction- } \\
\text { Organizational Citizenship Behavior }\end{array}$ & 1,880 & 1,98 & Tidak Terbukti \\
\hline $\begin{array}{l}\text { Perceived Organizational Citizenship Behavior-Job } \\
\text { Satisfaction-Organizational Citizenship Behavior }\end{array}$ & $-1,345$ & 1,98 & Tidak Terbukti \\
\hline $\begin{array}{l}\text { Employee Participation in Decision Making-Job } \\
\text { Satisfaction-Organizational Citizenship Behavior }\end{array}$ & 0,86 & 1,98 & Tidak Terbukti \\
\hline $\begin{array}{l}\text { Career Development-Job Satisfaction-Organizational } \\
\text { Citizenship Behavior }\end{array}$ & 2,302 & 1,98 & Terbukti \\
\hline $\begin{array}{l}\text { Safety and Health Compliance-Job Satisfaction- } \\
\text { Organizational Citizenship Behavior }\end{array}$ & 1,018 & 1,98 & Tidak Terbukti \\
\hline Sumber : Data Primer, diolah, 2019 & & &
\end{tabular}

\section{PEMBAHASAN}

Perceived co-worker dinilai responden sebagai berikut: rekan kerja saya peduli dengan keselamatan dan kesehatan saya $(4,03)$, rekan kerja saya saling mendorong dalam pekerjaan $(4,08)$, rekan kerja saya sangat membantu dalam pekerjaan $(4,05)$, rekan kerja saya memberi saran yang berguna masalah pekerjaan (4,03), rekan kerja saya mengambil alih tugas ketika saya merasa lelah $(3,84)$, semua memiliki nilai rata-rata $>3$ dari skala 1 sampai dengan 5. Temuan menyatakan bahwa perceived co-worker bukan penyebab job satisfaction (Matijaš \& Brdovčak, 2018)

Job satisfaction memiliki ukuran sebagai berikut: saya merasa cukup puas dengan pekerjaan saya saat ini $(3,81)$, hampir setiap hari saya antusias dengan pekerjaan saya saat ini $(3,82)$, saya menemukan kenikmatan nyata dalam pekerjaan saya $(3,66)$. Nilai dari pertanyaan job satisfaction > 3 yang menunjukkan adanya job satisfaction, namun indikator yang diukurkan tersebut ternyata tidak menjadi penyebab job satisfaction karyawan. Perlu dilakukannya peningkatan terhadap dukungan dari rekan kerja sehingga karyawan merasakan nyaman pada organisasi, bentuk perhatian yang diberikan sesama rekan kerja berbeda dengan dukungan yang diberikan oleh atasan maupun organisasi, bentuk dari dukungan rekan kerja biasanya dalam bentuk rasa empati dan sosial, untuk itu perlu diperbaiki kembali bagaimana membangun hubungan yang harmonis dengan sesama karyawan.

Perceived supervisior support dinilai responden sebagai berikut: atasan memberikan perhatian untuk keselamatan dan kesehatan saya $(3,96)$, atasan bersedia mendengarkan masalah saya tentang keamanan dan kesehatan $(3,92)$, atasan menempatkan penekanan yang kuat pada keamanan dan kesehatan $(3,92)$, atasan mendorong saya untuk melakukannya perubahan untuk meningkatkan kesehatan saya $(3,78)$, atasan prihatin tentang kesejahteraan dari orang-orang di bawahnya $(3,76)$, atasan memperhatikan apa yang saya katakana $(3,82)$, atasan mendorong kami untuk melaporkan keselamatan dan ketidaksesuaian kesehatan (3,86). Temuan menyatakan bahwa perceived supervisior support berpengaruh terhadap job satisfaction, hasil penelitian sesuai dengan penelitian yang dilakukan oleh Yang et al., (2018). Perceived Supervisior Support dalam organisasi diyakini dapat 
membuat individu merasa nyaman dan merasa senang bekerja dalam organisasi, karena atasan mereka memberikan perhatian serta kepercayaan untuk melaksanakan pekerjaan yang menjadi tanggung jawab individu, ketika karyawan merasa memiliki peran kerja sesuai yang diharapkan oleh atasan mereka dan atasan selalu memberikan evaluasi terhadap pekerjaannya, mereka akan menemukan lebih banyak kebermaknaan dalam pekerjaan.

Hipotesis ketiga yang menyatakan perceived organizational support berpengaruh terhadap job satisfaction, ditolak. Statistik deskriptif dari indikator perceived organizational support dengan urutan terkecil hingga rata-rata terbesar adalah sebagai berikut: organisasi memberikan perhatian terhadap pekerjaan yang saya lakukan (2,71), organisasi peduli dengan apa pun keluhan dari saya $(2,73)$, organisasi menghargai usaha ekstra dari saya $(2,80)$, organisasi membantu, saat saya merasa bingung menyelesaikan pekerjaan $(3,05)$. Nilai dari rata-rata pertanyaan, masih ada yang kurang dari 3, perlu ada peningkatan pada perhatian dan kepedulian organisasi pada karyawan sehingga karyawan akan merasa puas dengan organisasi. Hasil perceived organizational support tersebut tidak menciptakan kepuasan kerja bagi karyawan, temuan tidak mendukung (Mayes et al., 2017; Maden \& Kabasakal, 2014). Karyawan didalam organisasi tidak hanya merasa puas dengan apresiasi yang diberikan organisasi melalui evaluasi kinerja mereka yang positif, namun karyawan juga merasa puas dengan dukungan organisasi ketika organisasi menghargai kontribusi mereka dan bersikap peduli terhadap kesejahteraan karyawan.
Hipotesis keempat yang menyatakan employee participation in decision making berpengaruh terhadap job satisfaction, ditolak. Statistik deskriptif dari indikator employee participation in decision making dengan urutan rata-rata terbesar hingga terkecil adalah sebagai berikut: saya berusaha keras untuk menyelesaikan pekerjaan saya $(4,21)$, saya berusaha sekuat tenaga untuk melakukan pekerjaan saya dengan baik (4,21), saya mengerahkan kemampuan dengan penuh untuk pekerjaan saya $(4,10)$, saya mengusahakan banyak energi pada pekerjaan saya $(4,07)$, saya mengabdikan banyak energi untuk pekerjaan saya $(3,95)$, saya didorong untuk menyarankan ideide untuk meningkatkan kemajuan organisasi $(3,93)$. Temuan menyatakan bahwa employee participation in decision making bukan penyebab job satisfaction. Hasil temuan tidak mendukung penelitian yang dilakukan oleh Scott-Ladd, Travaglione, \& Marshall (2006); Muindi (2014). Dilihat dari nilai statistik deskriptif pada penilaian paling rendah terdapat pada pertanyaan saya didorong untuk menyarankan ide-ide untuk meningkatkan kemajuan organisasi, keterlibatan karyawan untuk kemajuan organisasi perlu ditingkatkan, karyawan yang lebih banyak terlibat dalam kegiatan organisasi akan mengerahkan segala kemampuan dan energinya pada organisasi.

Hipotesis kelima yang menyatakan bahwa career development berpengaruh terhadap job satisfaction diterima. Temuan penelitian ini, sesuai dengan penelitian yang dilakukan oleh Naway \& Haris (2017); Saleem et al., (2013) bahwa career development berpengaruh terhadap job satisfaction. Munculnya kepuasan kerja antara lain didorong oleh faktor pengembangan karier yang mengalami kemajuan 
dengan baik. Pengembangan karier dalam suatu organisasi adalah salah satu objek penting, sehingga dapat memberi pengaruh pada sikap dan perilaku karyawan serta kondisi emosional mereka. Seperti yang dibahas sebelumnya, kepuasan kerja itu menunjukkan perasaan yang menyenangkan atau emosional kondisi. Karena itu, jika seorang karyawan memiliki persepsi yang baik tentang implementasi pengembangan karir, dapat memberikan yang positif berdampak pada munculnya kepuasan kerja. Dengan perkembangan dari karir yang baik, akan memungkinkan karyawan mendapatkan promosi dengan cepat, menikmati pekerjaan mereka dengan senang hati, dan merasa tertantang, sehingga karyawan puas dengan kondisi tersebut (Naway \& Haris, 2017).

Hipotesis keenam yang menyatakan safety and health Compliance berpengaruh terhadap Job Satisfaction, ditolak. Temuan ini tidak mendukung riset terdahulu dari (Game, 2007) bahwa bentuk pemberian keselamatan dan kesehatan kepada karyawan yang telah dilakukan organisasi ternyata tidak membentuk rasa kepuasan pada individu karyawan. Safety and Health Compliance dinilai responden sebagai berikut: saya melakukan pekerjaan dengan mengutamakan prosedur $(2,79)$, saya mengambil jalan pintas yang melibatkan sedikit atau tidak sama sekali risiko $(3,54)$, saya menggunakan prosedur kesehatan sesusai peraturan yang berlaku $(2,68)$. Hasil statistik deskriptif menunjukkan bahwa masih ada nilai yang berada dibawah 3 , perlu dilakukan peningkatan terhadap keselamatan dan kepatuhan kerja yang dilakukan organisasi dalam prosedur keselamatan dan kesehatan. Keselamatan dan kesehatan kerja dapat mempengaruhi kepuasan karyawan pada organisasi, dengan adanya keselamatan dan kesehatan di tempat kerja dapat menggambarkan bahwa organisasi peduli dengan keselamatan dan kesehatan karyawan di tempat bekerja.

$$
\text { Hipotesis ketujuh yang }
$$
menyatakan perceived co workers terhadap organizational citizenship behavior, ditolak. Perceived co-worker dinilai responden sebagai berikut: rekan kerja saya peduli dengan keselamatan dan kesehatan saya $(4,03)$, rekan kerja saya saling mendorong dalam pekerjaan $(4,08)$, rekan kerja saya sangat membantu dalam pekerjaan $(4,05)$, rekan kerja saya memberi saran yang berguna masalah pekerjaan $(4,03)$, rekan kerja saya mengambil alih tugas ketika saya merasa lelah $(3,84)$. Responden yang diambil dari penelitian ini berumur 20-30 tahun dengan presentase $71,8 \%$, menunjukkan bahwa mereka termasuk dalam generasi ini, dibutuhkan perhatian yang lebih besar dari rekan kerja agar karyawan mau untuk terlibat dalam kegiatan organisasi. Hubungan dengan rekan kerja yang baik di tempat kerja akan mempengaruhi perasaan dan perilaku di tempat kerja. Temuan ini tidak sesuai dengan riset yang dilakukan oleh Ladd \& Henry, 2000; Farrell \& Finkelstein, 2011; Ottu, Ayangeaor \& Umoren, 2017 yang membuktikan perceived co-workers bepengaruh terhadap organizational citizenship behavior.

Hipotesis kedelapan yang menyatakan perceived supervisior support berpengaruh terhadap organizational citizenship behavior, diterima. Oleh karena itu atasan perlu meningkatkan implementasi mendukung karyawan di dalam organisasi, karyawan akan merasa atasan mendukung mereka didalam bekerja karyawan akan membalas dengan sikap rajin dan mengerahkan segala pikiran serta 
kemampuannya kepada organisasi, sebaliknya karyawan akan menunjukkan perilaku rendah dan malas untuk melaksanakan tugas kantor apabila karyawan. merasa dukungan yang diberikan atasan terhadapnya dirasakan kurang dan tidak sesuai yang diinginkan oleh persepsi karyawan. Penelitian sesuai dengan penelitian yang dilakukan oleh (Akram et al., 2018; Kartika et al., 2017; Yui-Tim Wonga, 2012).

Hipotesis kesembilan yang menyatakan perceived organizational support berpengaruh terhadap organizational citizenship behavior, ditolak. Statistik deskriptif dari indikator perceived organizational support dengan urutan terkecil hingga rata-rata terbesar adalah sebagai berikut: organisasi memberikan perhatian terhadap pekerjaan yang saya lakukan $(2,71)$, organisasi peduli dengan apa pun keluhan dari saya $(2,73)$, organisasi menghargai usaha ekstra dari saya $(2,80)$, organisasi membantu, saat saya merasa bingung menyelesaikan pekerjaan $(3,05)$. Temuan dalam penelitian ini menyatakan perceived organizational support bukan penyebab organizational citizenship behavior, perceived organizational support. Organizational Citizenship Behavior memiliki ukuran sebagai berikut: saya melakukan pekerjaan ekstra selain tugas utama di organisasi yang bukan bidang saya juga $(3,76)$, saya dikenal suka bekerja ekstra di tempat kerja ini $(3,71)$, saya menemukan cara baru yang dapat diajukan sebagai saran untuk meningkatkan kinerja $(3,74)$, saya bersedia menjadi sukarelawan pengelola di tempat saya bekerja $(3,68)$, saya bisa meminta prosedur imbalan sesuai etika dan moral $(3,63)$. Berdasarkan nilai statistik deskriptif yang dimiliki dapat dilihat bahwa nilai perceived organizational support ada yang dibawah 3, hal ini menjadi evaluasi bagi organisasi untuk melakukan perbaikan dalam memberikan dukungan dan perhatian kepada karyawan sehingga karyawan akan meningkatkan kinerjanya, bahkan mereka mau untuk bekerja diluar job desk yang dimiliki. Karyawan melakukan organizational citizenship behavior bukan hanya untuk mendapatkan perhatian dari organisasi, tetapi berdasarkan kesadaran dari dirinya sendiri. Temuan penelitian ini tidak sesuai dengan penelitian yang dilakukan oleh Wong \& Ngo (2012); Newman, Nielsen and Miao (2015) bahwa perceived organizational support berpengaruh terhadap organizational citizenship behavior.

Employee Participation Decision in Making memiliki pertanyaan positif: Saya didorong untuk menyarankan ideide untuk meningkatkan kemajuan organisasi (3,93); Saya mengerahkan kemampuan dengan penuh untuk pekerjaan saya $(4,10)$; Saya mengabdikan banyak energi untuk pekerjaan saya $(3,95)$; Saya berusaha sekuat tenaga untuk melakukan pekerjaan saya dengan baik $(4,21)$, Saya berusaha keras untuk menyelesaikan pekerjaan saya $(4,21)$, Saya mengusahakan banyak energi pada pekerjaan saya $(4,07)$. Nampak pada pernyataan dari jawaban responden dengan rata-rata > 3 . Penelitian ini tidak mendukung penelitian terdahulu bahwa Employee Participation Decision in Making berpengaruh terhadap Organizational citizenship behavior seperti pada penelitian (Veshaghi, 2016). Berdasarkan data yang diperoleh untuk dari pengisian kuesioner, karyawan memberikan energinya dalam perusahaan masih dalam kategori normal dengan presentase sebesar $58.0 \%$, karyawan enggan untuk terlibat dalam banyak kegiatan dalam organisasi, mereka lebih memilih untuk bekerja sesuai dengan job desk yang dimiliki, mereka menerapkan work life balance dalam organisasi. 
Hasil penelitian menunjukkan bahwa career development untuk karyawan berpengaruh dalam pencapaian organizational citizenship behavior. Career development dinilai responden sebagai berikut: organisasi saya sangat memperhatikan perkembangan karir saya $(3,74)$, organisasi saya mendesain jalur karier untuk saya $(3,62)$ ). Nampak pada pernyataan dari jawaban responden dengan rata-rata $>3$. Temuan penelitian ini sesuai dengan penelitian $\mathrm{Al}$ Shawabkeh (2017) bahwa career development berpengaruh terhadap organizational citizenship behavior. Responden yang mengisi kuesioner rata-rata memiliki pendidikan terakhir SMA dengan presentase $50,4 \%$, bentuk pengembangan karier diperlukan dalam meningkatan kinerja karyawan, karyawan akan merasakan happiness at work di tempat kerja, ketika organisasi mendukung segala hal peningkatan kinerja mereka, bentuk pengembangan karier yang dapat diberikan oleh organisasi seperti studi lanjut, pelatihan, dll.

Hipotesis yang menyatakan bahwa safety and health compliance yang dirasakan mempengaruhi organizational citizenship behavior, diterima. Berdasarkan tes, safety and health compliance berpengaruh signifikan terhadap organizational citizenship behavior $(\mathrm{p}<5 \%)$. Hasil ini konsisten dengan penelitian lain sebelumnya yang menyatakan safety and health compliance secara signifikan mendukung terhadap organizational citizenship behavior. Tingkat kesehatan dan keselamatan kerja merupakan hal yang penting dalam organisasi, dengan adanya tingkat kesehatan dan keselamatan kerja karyawan akan merasa terlindungi dalam pekerjaan terhadap tingkat kecelakaan kerja. Jika dilihat dari responden yang mengisi penelitian ini, jumlah karyawan terbanyak adalah mereka yang memiliki gender perempuan, sehingga diperlukan kesehatan dan keselamatan lebih tinggi terhadap pekerjaannya. Ketika karyawan merasa organisasi peduli terhadap karyawan, mereka akan merasa nyaman terhadap organisasinya dan akan meningkatkan kinerja dengan melakukan hal-hal positif yang memberikan keuntungan dan mengarah pada OCB. Penelitian ini sesuai dengan penelitian yang dilakukan oleh peneliti terdahulu bahwa safety and health compliance berpengaruh terhadap organizational citizenship behavior (Xuesheng \& Xintao, 2011).

Job satisfaction memiliki ukuran sebagai berikut: saya merasa cukup puas dengan pekerjaan saya saat ini $(3,81)$, hampir setiap hari saya antusias dengan pekerjaan saya saat ini $(3,82)$, saya menemukan kenikmatan nyata dalam pekerjaan saya $(3,66)$. Organizational Citizenship Behavior memiliki ukuran sebagai berikut: saya melakukan pekerjaan ekstra selain tugas utama di organisasi yang bukan bidang saya juga $(3,76)$, saya dikenal suka bekerja ekstra di tempat kerja ini $(3,71)$, saya menemukan cara baru yang dapat diajukan sebagai saran untuk meningkatkan kinerja $(3,74)$, saya bersedia menjadi sukarelawan pengelola di tempat saya bekerja $(3,68)$, saya bisa meminta prosedur imbalan sesuai etika dan moral $(3,63)$. Temuan penelitian ini sesuai dengan penelitian yang dilakukan oleh Ladebo (2008); Tang (2008) bahwa job satisfaction berpengaruh terhadap organizational citizenship behavior. Kepuasan kerja dirasakan ketika karyawan merasakan happiness at work di organisasi, sehingga membuat karyawan bertahan ditempat kerja. 


\section{SIMPULAN DAN SARAN}

Temuan penelitian menunjukkan bahwa kepedulian terhadap rekan kerja, perlu ditingkatkan, terutama dalam hal membantu pekerjaan rekan kerja dan mengambil alih tugas ketika karyawan berhalangan hadir baik karena sakit maupun kelelahan. Berdasarkan jawaban responden masih ada yang menjawab point sangat tidak setuju maupun tidak setuju. Organisasi dapat meningkatkan bentuk kerjasama yang baik terhadap sesama karyawan dalam bentuk kegiatan capacity building, atau family gathering sehingga kerjasama sesama karyawan ditempat kerja akan meningkat.

Perceived Supervisior Support, organisasi perlu meningkatkan kesejahteraan karyawan diorganisasi, sehingga karyawan merasa organisasi menghargai kinerjanya, karyawan akan meningkatkan keterlibatan dalam bekerja, sehingga menimbulkan sikap OCB yang lebih besar. Bentuk perhatian atasan kepada karyawan dapat berupa memotivasi karyawan, menjaga hubungan sosial yang baik dengan karyawan dan mengapresiasi pekerjaan karyawan.

Dukungan organisasi terhadap karyawan perlu mendapatkan perhatian yang lebih besar, dapat dilihat dari tabel analisis deskriptif bahwa responden yang mengisi kuesioner memilih jawaban nomer 1 dan 2. Bentuk sikap peduli, dan support dari organisasi sangat diperlukan oleh karyawan sehingga mereka merasa puas pada pekerjaan yang dilakukan dan tumbuh sikap OCB pada organisasi, sehingga bentuk kerja lembur yang dilakukan oleh karyawan bukan hanya sebagai untuk mencari perhatian atasan dan organisasi semata agar terlihat rajin, namun muncul pada sikap karyawan itu sendiri.

Bentuk partisipasi karyawan juga perlu ditingkatkan, sehingga kepuasan kerja dan organizational citizenship behavior dapat dirasakan oleh karyawan. Berdasarkan hasil pengisi kuesioner, energi yang diberikan karyawan pada pekerjaan masih rendah, sehingga saran yang dapat diberikan oleh organisasi untuk meningkatkan energy yang diberikan karyawan pada organisasi adalah melibatkan karyawan untuk berpatisipasi dalam kegiatan organisasi, ketika karyawan berpatisipasi dalam organisasi mereka akan beradaptasi dengan organisasi ditempat kerja, memahami apa yang dibutuhkan organisasi untuk berkembang sehingga karyawan akan mengerahkan segala kemampuan yang dimiliki untuk mencapai tujuan.

Bentuk OCB yang ditimbulkan oleh karyawan salah satu berasal dari pengembangan karier karyawan. Pengembangan karier karyawan yang ada diorganisasi juga perlu diperhatikan, karyawan jangan hanya dituntut dalam hal meningkatakan kinerja kepada organisasi, namun bentuk timbal balik juga harus dirasakan oleh karyawan dalam hal karier mereka. Bentuk pengembangan karier yang dapat diberikan oleh karyawan seperti kesempatan untuk mempromosikan diri mereka untuk jabatan yang lebih baik di organisasi, pelatihan, dan pendidikan lanjut.

Karyawan yang bekerja didalam organisasi tidak hanya membutuhkan dukungan baik dari atasan maupun organisasi, tetapi dibutuhkan juga safety and health compliance bagi karyawan, bentuk respon dari responden yang mengisi kuesioner terlihat bahwa masih $32 \%$ karyawan masih mengisi jawaban sangat tidak setuju dan tidak setuju, bentuk prosedur keselamatan dan kesehatan karyawan perlu ditingkatkan. Bentuk safety and health compliance yang dapat ditawarkan oleh organisasi kepada karyawan adalah jaminan kerja berupa asuransi, maupun BPJS ketenagakerjaan. 


\section{DAFTAR PUSTAKA}

Akram, A., Kamran, M., Iqbal, M. S., Habibah, U., \& Atif Ishaq, M. (2018). The impact of supervisory justice and perceived Supervisor support on organizational citizenship behavior and commitment to supervisor: the mediating role of trust. Cogent Business and Management, 5(1), 1-17. https://doi.org/10.1080/23311975.2018.149390 2

Al-Shawabkeh, K. M. (2017). Career Path Development and its Impact on Organizational Citizenship Behavior in Greater Amman Municipality. International Journal of Business and Management, 12(3), 79 . https://doi.org/10.5539/ijbm.v12n3p79

Carmeli, A., Shalom, R., \& Weisberg, J. (2007). Considerations in organizational career advancement: What really matters. Personnel Review, 36(2), 190-205. https://doi.org/10.1108/00483480710726109

Crow, M. S., Lee, C., \& Joo, J. (2012). Organizational justice and organizational commitment among South Korean police officers. An investigation of job satisfaction as a mediator. Policing: An International Journal of Police Strategies \& Management, 35(2), 402-423.

https://doi.org/10.1108/13639511211230156

Farrell, S. K., \& Finkelstein, L. M. (2011). The Impact of Motive Attributions on Coworker Justice Perceptions of Rewarded Organizational Citizenship Behavior. Journal of Business and Psychology, 26(1), 57-69. https://doi.org/10.1007/s10869-010-9174-5

Game, A. M. (2007). Workplace boredom coping: Health, safety, and HR implications. Personnel Review, 36(5), 701-721. https://doi.org/10.1108/00483480710774007

Huo, M. L., \& Boxall, P. (2018). Are all aspects of lean production bad for workers? An analysis of how problem-solving demands affect employee well-being. Human Resource Management Journal, 28(4), 569-584. https://doi.org/10.1111/1748-8583.12204

Kartika, E. W., Kaihatu, T. S., Adiwijaya, M., \& Nugroho, A. (2017). Perceived Supervisor Support (PSS), Affective Commitment, and Organizational Citizenship Behavior (OCB): Study in Indonesian Context. International Research Conference on Economics and Business, 12.

Kozlenkova, I. V., Samaha, S. A., \& Palmatier, R.
W. (2014). Resource-based theory in marketing. Journal of the Academy of Marketing Science, 42(1), 1-21. https://doi.org/10.1007/s11747-013-0336-7

Khan, S., Mahmood, A., Kanwal, S., \& Latif, Y. (2015). How perceived supervisor support effects workplace deviance? Mediating role of perceived organizational support. Pakistan Journal of Commerce and Social Sciences (PJCSS), 9(3), 940-967.

Ladd, D., \& Henry, R. A. (2000). Helping coworkers and helping the organization: The role of support perceptions, exchange ideology, and conscientiousness. Journal of Applied Social Psychology, 30(10), 2028-2049. https://doi.org/10.1111/j.1559-

1816.2000.tb02422.x

Ladebo, O. J. (2008). Perceived supervisory support and organisational citizenship behaviours: Is job satisfaction a mediator? South African Journal of Psychology, 38(3), 479-488.

https://doi.org/10.1177/008124630803800303

Liu, Y. (2009). Perceived organizational support and expatriate organizational citizenship behavior: The mediating role of affective commitment towards the parent company. Personnel Review, 38(3), 307-319. https://doi.org/10.1108/00483480910943359

Maden, C., \& Kabasakal, H. (2014). The simultaneous effects of fit with organizations, jobs and supervisors on major employee outcomes in Turkish banks: Does organizational support matter? International Journal of Human Resource Management, 25(3), 341-366. https://doi.org/10.1080/09585192.2013.789446

Matijaš, \& Brdovčak, M. M. \& B. (2018). Job resources and satisfaction across gender: the role of work-family conflict. Journal of Managerial Psychology, 33(4-5), 372-385. https://doi.org/10.1108/JMP-09-2017-0306

Mayes, B. T., Finney, T. G., Johnson, T. W., Shen, J., \& Yi, L. (2017). The effect of human resource practices on perceived organizational support in the People's Republic of China. International Journal of Human Resource Management, 28(9), 1261-1290. https://doi.org/10.1080/09585192.2015.111476 8

Muindi, F. (2014). The Relationship between Participation in Decision Making and Job Satisfaction among Academic Staff in the School of Business, University of Nairobi. 
Journal of Human Resources Management Research, 2011, 1-34. https://doi.org/10.5171/2011.246460

Naway, F. A., \& Haris, I. (2017). The Effect of Career Development , Perception of Organizational Justice and Job Satisfaction on Teacher , s Organizational Citizenship Behavior. International Review of Management and Marketing, 7(2), 17-21.

Newman, A., Nielsen, I., \& Miao, Q. (2015). The impact of employee perceptions of organizational corporate social responsibility practices on job performance and organizational citizenship behavior: evidence from the Chinese private sector. International Journal of Human Resource Management, 26(9), $\quad$ 1226-1242. https://doi.org/10.1080/09585192.2014.934892

Ottu, I., Ayangeaor, J. I., \& Umoren, A. (2017). Workplace Citizenship Behaviours : Optimising Roles of Co- Worker Relationship Maintenance , Workplace Incentives and Workplace Citizenship Behaviours: Optimizing Roles of Co Co- worker Relationship Maintenance , Workplace Incentives and Leadership Quali. International Journal of Social Sciences, 11(1), 68-81.

Puah, L. N., Ong, L. D., \& Chong, W. Y. (2016). The effects of perceived organizational support, perceived supervisor support and perceived coworker support on safety and health compliance. International Journal of Occupational Safety and Ergonomics, 22(3), 333-339.

https://doi.org/10.1080/10803548.2016.115939 0

Prakoso, G. A. and Listiara, A. (2017) 'Hubungan Antara Happiness At Work Dengan Organizational Citizenship Behavior Pada Karyawan Pt. Pln (Persero) Distribusi Jawa Tengah Dan Daerah Istimewa Yogyakarta Dan Pt. Pln (Persero) Apj Magelang', Empati, 6(1), pp. 173-180.

Rich, B. L. Jeffrey A. L., dan Eean R. C. (2010). "Job Engagement: Antecedents and Effects on Job Performance." Academy of Management Journal. 53 (3): 617-635.

Saleem, Y., Kamran, M. R., Sabir, F., \& Iqbal, J. (2013). Career Development an Imperative of Job Satisfaction and Career Commitment: Empirical Evidence from Pakistani Employees in Banking Sector. European Journal of Business and Management, 5(21), 108-119.

Scott-Ladd, B., Travaglione, A., \& Marshall, V.
(2006). Causal inferences between participation in decision making, task attributes, work effort, rewards, job satisfaction and commitment. Leadership and Organization Development Journal, 27(5), 399-414. https://doi.org/10.1108/01437730610677990.

Shim, D. C., \& Rohrbaugh, J. (2014). An Explanation of Differences Between Government Offices in Employees' Organizational Citizenship Behaviour. Public Management Review, 16(6), 807-829. https://doi.org/10.1080/14719037.2012.757352

Tang, D. A. F. and T. L.-P. (2008). Article information: Management Decision, 17(4), 287-297.

Veshaghi, D. M. H. khasmafkan N. N. C. B. M. R. (2016). Analysis of Organizational Justice (OJ) in relation to Participation in Decision-Making and Organizational Citizenship Behavior (OCB). Researchgate.Net, (June).

Xiao, H., Wang, Y., Li, W., \& Ma, Z. (2017). Nankai Business Review International Article information. Nankai Business Review International, $\quad 8(1), \quad 100-120$. https://doi.org/10.1108/NBRI-10-2016-0035

Yang, F., Liu, J., Huang, X., Qian, J., Wang, T., Wang, Z., \& Yu, H. (2018). How supervisory support for career development relates to subordinate work engagement and career outcomes: The moderating role of task proficiency. Human Resource Management Journal, 28(3), 496-509. https://doi.org/10.1111/1748-8583.12194

Yui-Tim Wonga, C.-S. W. \& H.-Y. N. (2012). The effects of trust in organisation and perceived organisational support on organisational citizenship behaviour: A test of three competing models. International Journal of Human Resource Management, 23(2), 278293. https://doi.org/10.1080/09585192.2011.610966 Wernerfelt, B. (1984). Harmonised implementation of Application-Specific Messages (ASMs). Strategic Management Journal, 5(2), 171-180. https://doi.org/10.1002/smj.4250050207

Wong, Y. T., Wong, C. S. and Ngo, H. Y. (2012) 'The effects of trust in organisation and perceived organisational support on organisational citizenship behaviour: A test of three competing models', International Journal of Human Resource Management, 23(2), pp. 278-293. doi: 10.1080/09585192.2011.610966.

Xuesheng, D. and Xintao, Z. (2011) 'An Empirical Investigation of the Influence of Safety Climate 
on Safety Citizenship Behavior in Coal Mine', Procedia Engineering, 26(3), pp. 2173-2180. doi: 10.1016/j.proeng.2011.11.2422.

Zhang, Y., Farh, J., \& Wang, H. (2011). The International Journal of Human Organizational antecedents of employee perceived organizational support in China: a grounded investigation. (November 2014), 37-41. https://doi.org/10.1080/09585192.2011.560886 